\title{
Comparison of Structure and Properties of Femtosecond and Nanosecond Laser-Structured Silicon
}

\section{Citation}

Crouch, C. H., J. E. Carey, J. M. Warrender, Michael J. Aziz, Eric Mazur, and F. Y. Genin. 2004. Comparison of structure and properties of femtosecond and nanosecond laser-structured silicon. Applied Physics Letters 84, no. 11: 1850-1852

\section{Published Version}

http://dx.doi.org/10.1063/1.1667004

\section{Permanent link}

http://nrs.harvard.edu/urn-3:HUL.InstRepos:10345121

\section{Terms of Use}

This article was downloaded from Harvard University's DASH repository, and is made available under the terms and conditions applicable to Other Posted Material, as set forth at http:// nrs.harvard.edu/urn-3:HUL.InstRepos:dash.current.terms-of-use\#LAA

\section{Share Your Story}

The Harvard community has made this article openly available.

Please share how this access benefits you. Submit a story.

\section{Accessibility}




\title{
Comparison of structure and properties of femtosecond and nanosecond laser-structured silicon
}

\author{
C. H. Crouch, ${ }^{\text {a) }}$ J. E. Carey, J. M. Warrender, M. J. Aziz, and E. Mazur ${ }^{\text {b) }}$ \\ Division of Engineering and Applied Sciences, Harvard University, Cambridge, Massachusetts 02138 \\ F. Y. Génin \\ Lawrence Livermore National Laboratory, Livermore, California 94550
}

(Received 8 August 2003; accepted 7 January 2004)

\begin{abstract}
We compare the optical properties, chemical composition, and crystallinity of silicon microstructures formed in the presence of $\mathrm{SF}_{6}$ by femtosecond laser irradiation and by nanosecond laser irradiation. In spite of very different morphology and crystallinity, the optical properties and chemical composition of the two types of microstructures are very similar. The structures formed with femtosecond (fs) pulses are covered with a disordered nanocrystalline surface layer less than $1 \mu \mathrm{m}$ thick, while those formed with nanosecond (ns) pulses have very little disorder. Both ns-laser-formed and fs-laser-formed structures absorb near-infrared (1.1-2.5 $\mu \mathrm{m})$ radiation strongly and have roughly $0.5 \%$ sulfur impurities. (C) 2004 American Institute of Physics.
\end{abstract}

[DOI: $10.1063 / 1.1667004]$

Many types of micrometer-scale surface structures develop spontaneously on silicon surfaces after repeated pulsed laser irradiation. ${ }^{1}$ In particular, sharp conical microstructures form on silicon surfaces in the presence of $\mathrm{SF}_{6}$ with either femtosecond (fs) $)^{2}$ or nanosecond $(\mathrm{ns})^{3}$ laser irradiation. Mazur and co-workers previously found that fs-laser-formed structures exhibit below-band gap light absorption and photocurrent generation; ${ }^{4,5}$ these remarkable optoelectronic properties are attributed to sulfur impurities in a microcrystalline surface layer. ${ }^{4,6}$ Although the fs-laser-formed and nslaser-formed structures resemble one another superficially, the differences in formation conditions and morphology suggest that the formation mechanisms of the two types of structures differ significantly. We set out to determine whether the optoelectronic properties, chemical composition, and crystallinity of the ns-formed and fs-formed structures also differ.

We made samples by irradiating a silicon wafer with a train of laser pulses in a vacuum chamber backfilled with $\mathrm{SF}_{6} \cdot{ }^{4}$ (Mazur and co-workers found previously that the doping, resistivity, and crystal plane of the substrate do not affect the optical properties. ${ }^{6}$ ) The pressure of $\mathrm{SF}_{6}$ was chosen to match the conditions used in initial reports of these structures (0.67 bar of $\mathrm{SF}_{6}$ with fs pulses ${ }^{2}$ and 1 bar of $\mathrm{SF}_{6}$ with ns pulses $^{3}$ ). A regeneratively amplified Ti:sapphire laser delivered a train of $800 \mathrm{~nm}, 100$ fs pulses with a Gaussian spatial profile; the average fluence of the laser spot was $8 \mathrm{~kJ} / \mathrm{m}^{2}$. A $\mathrm{KrF}^{+}$excimer laser delivered a train of $248 \mathrm{~nm}, 30 \mathrm{~ns}$ laser pulses with a flat-top spatial profile and a fluence of 30 $\mathrm{kJ} / \mathrm{m}^{2}$. Irradiation creates an array of structures on the sample surface only in the region illuminated by the laser.

We structure areas up to $10 \mathrm{~mm} \times 10 \mathrm{~mm}$ by scanning the laser beam across the sample. The average number of laser pulses on any part of the surface is determined by the scan speed, the size of the laser spot on the sample surface,

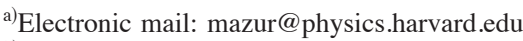

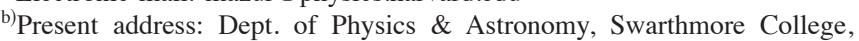
Swarthmore, PA 19081.
}

and the laser repetition rate. To produce fully developed spikes, an average of 500 laser pulses was delivered to each area with fs pulses, ${ }^{4}$ and an average of 1500 laser pulses with ns pulses. ${ }^{3}$

Images of the structures are shown in Fig. 1. The structures formed with the fs laser are one-fifth the size of those formed with the ns laser. The fs-formed structures are roughly $8 \mu \mathrm{m}$ tall and separated by $4 \mu \mathrm{m}$; the ns-formed structures are roughly $40 \mu \mathrm{m}$ tall and separated by $20 \mu \mathrm{m}$. The tips of the fs-formed structures are at the level of the original surface of the wafer [Fig. 1(e)], while the ns-formed structures protrude above the original surface [Fig. 1(f)]. Fi-

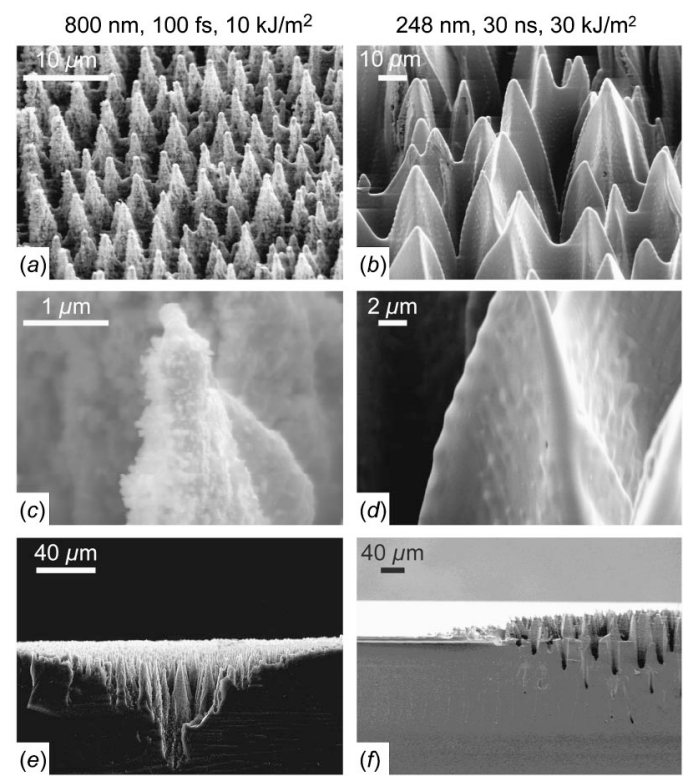

FIG. 1. Scanning electron micrographs of laser-microstructured Si surface formed in $\mathrm{SF}_{6}[(\mathrm{a})$, (c), (e)] with fs laser pulses, and [(b), (d), (f)] with ns laser pulses. In (a)-(d) the sample is viewed at $45^{\circ}$ to the normal; in (e) and (f) the sample is snapped in half and viewed edge-on. 


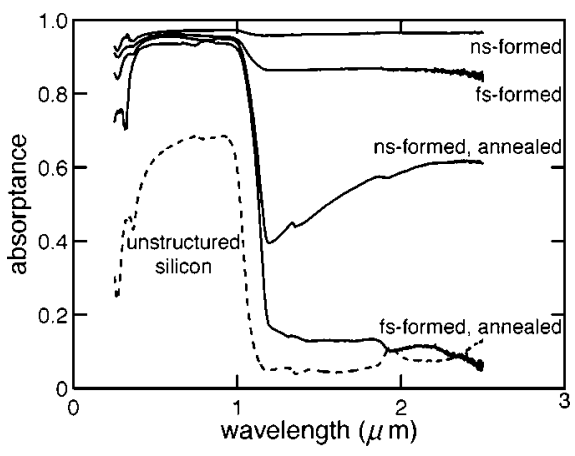

FIG. 2. Dependence of absorptance $(A)$ on wavelength of fs-laser-formed and ns-laser-formed microstructures, before and after thermal annealing at $875 \mathrm{~K}$ for $45 \mathrm{~min}$ in flowing Ar. The absorptance of the unstructured $\mathrm{Si}$ substrate is also shown.

nally, the fs-formed structures are covered with nanoparticles $10-50 \mathrm{~nm}$ in diameter that appear to have been deposited on the structures [Fig. 1(c)], while the surface of the ns-formed structures is much smoother, with $500 \mathrm{~nm}$ size protrusions that appear to grow out of the surface [Fig. 1(d)].

We measured total hemispherical (specular and diffuse) reflectance $(R)$ and transmittance $(T)$ to determine the absorptance $(A=1-R-T)$ of the structured surfaces. Measurements were performed with a Hitachi U-4001 UV-VIS spectrophotometer equipped with an integrating sphere detector. Figure 2 shows the wavelength dependence of the absorptance of both structured surfaces and of the unstructured substrate silicon. The absorptance of the ns- and fsformed structures is very similar: near-unity, featureless absorptance from 0.4 to $1 \mu \mathrm{m}$, a small decrease in absorptance around $1.1 \mu \mathrm{m}$ (the band edge of ordinary silicon), and strong featureless absorptance from 1.1 to $2.5 \mu \mathrm{m}$. The absorptance at wavelengths longer than $1.1 \mu \mathrm{m}$ is particularly remarkable, as unstructured silicon is nearly transparent at these below-band gap wavelengths. The absorptance of the ns-structured material (98\% in the visible, $95 \%$ in the infrared) is somewhat stronger than that of the fs-structured material (95\% in the visible, $85 \%$ in the infrared).

Annealing the structured surfaces at $875 \mathrm{~K}$ for $45 \mathrm{~min}$ in flowing Ar leaves the visible absorptance essentially unchanged, but dramatically decreases the below-band gap absorptance (Fig. 2). The below-band gap absorptance of the ns-structured material changes less with annealing than that of the fs-structured material, and further annealing of the ns-structured material for up to $12 \mathrm{~h}$ causes little additional change. The morphology of the structures observed with scanning electron microscopy is unchanged by annealing at $875 \mathrm{~K} .{ }^{6}$ These observations suggest that the visible absorptance is due to amplification of the intrinsic visible absorptance of silicon by multiple reflections from the rough surface, but the below-band gap absorptance must come from electronic structure changes that are affected by annealing. (In the 40- $\mu \mathrm{m}$-deep ns-formed structures, the below-band gap absorptance should also be significantly amplified by multiple reflections; geometric effects may be less important to the below-band gap absorption in the fs-formed structures because these infrared wavelengths are not much less than the $8 \mu \mathrm{m}$ structure depth.)

Both the fs-structured and the ns-structured material exhibit photocurrent generation at wavelengths from 0.4 to Downloaded 21 May 2004 to 128.103.60.225. Redistribution subject
$1.65 \mu \mathrm{m}$; annealed samples have the greatest photoresponsivity. Both the fs-structured and the ns-structured materials, when annealed, have a photoresponsivity on the order of 10 $\mathrm{mA} / \mathrm{W}$ in the near infrared, with the responsivity at $1.31 \mu \mathrm{m}$ roughly twice that at $1.55 \mu \mathrm{m} .^{5}$ The infrared photoresponsivity is orders of magnitude lower in unannealed samples, although the below-band gap absorptance is several times greater; we surmise that annealing dramatically increases the mobility of the photocarriers, and the increased mobility more than compensates for the loss in absorptance.

Mazur and co-workers found previously that fs structuring must take place in the presence of sulfur to produce featureless, near-unity below-band gap absorption; structures formed in air or in vacuum do not absorb strongly at wavelengths longer than $1.1 \mu \mathrm{m} .^{7,8}$ Likewise, ns-formed structures formed in air do not absorb at below-band gap wavelengths. Sulfur impurities in the structures therefore appear to be critical to the below-band gap absorption.

To determine the concentration of sulfur impurities, we performed Rutherford backscattering spectrometry (RBS) and ion channeling on the structured samples, and compared the measured RBS spectra to simulated spectra from planar material. We measured the backscattering spectrum from 2.0 $\mathrm{MeV} \mathrm{He}{ }^{+}$with an annular solid state detector. As the RBS signal from deeper sulfur is masked by the silicon signal, the spectrum measures only the average sulfur concentration in the uppermost $100 \mathrm{~nm}$ of the surface. To simplify the RBS spectra, the surface oxide layer, which also includes fluorine impurities, is removed from the samples by etching for $4 \mathrm{~min}$ in 5\% HF; etching has no effect on the optical properties or surface morphology.

The RBS spectra of the fs-structured samples indicate that the sulfur concentration in the uppermost $100 \mathrm{~nm}$ is $0.7 \pm 0.1$ at. $\%$ before annealing and $0.5 \pm 0.1$ at. $\%$ after annealing. The sulfur signal obtained with ion channeling is slightly lower than that obtained with randomly aligned RBS, suggesting that some of the sulfur impurities are substitutional. The fs-structured samples channel poorly $\left(\chi_{\text {min }}^{(\mathrm{Si})}\right.$ $\sim 50 \%$ ), however, and the reduction in sulfur signal with channeling is comparable in magnitude to the possible sources of error. Hence we can only determine that between $20 \%$ and $70 \%$ of the sulfur in the unannealed fs-structured sample is substitutional, and we cannot determine how much sulfur is substitutional in the annealed fs-structured sample. In the ns-structured samples, the sulfur concentration in the observable near-surface region is $0.5 \pm 0.1$ at. \% before annealing, and $0.4 \pm 0.1$ at. $\%$ after annealing. The ns-structured samples show much stronger silicon channeling $\left(\chi_{\min }^{(\mathrm{Si})}\right.$ $=5.6 \%$ before and $6.6 \%$ after annealing), and nearly half of the sulfur is substitutional $(43 \% \pm 7 \%$ before and $48 \%$ $\pm 8 \%$ after annealing). The sulfur concentration is therefore very similar in the two types of structures, but much more of the affected material in the ns-structured samples is single crystal than in the fs-structured samples, and a great deal of the sulfur is definitely substitutional in the ns-structured samples. The sulfur may or may not be incorporated differently into the silicon in the two types of structures.

Given that annealing changes the optical properties dramatically, but only reduces the amount of observable sulfur by about $20 \%$, it is likely that the local environment of the to AIP license or copyright, see http://apl.aip.org/apl/copyright.jsp 


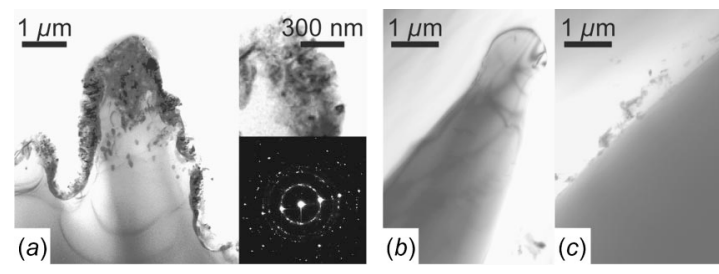

FIG. 3. Bright-field transmission electron micrographs of (a) cross section of fs-laser-formed microstructure [insets: (upper panel) higher magnification view of disordered material, (lower panel) selected area electron diffraction pattern obtained from the tip of the sample]; (b) cross section of tip of ns-laser-formed microstructure; and (c) cross section of side of ns-laserformed microstructure.

sulfur impurities is important to the optical properties. To learn more about the material structure, we examined cross sections of the structures with bright-field transmission electron microscopy (TEM). Figure 3 shows micrographs of a fs-structured sample [Fig. 3(a)] and a ns-structured sample [Figs. 3(b) and 3(c)]. The fs-formed structures consist of a core of undisturbed silicon covered with a highly disordered layer of silicon less than $1 \mu \mathrm{m}$ thick including nanocrystallites, nanopores, and sulfur impurities. Selected area diffraction [inset to Fig. 3(a)] indicates that the core is crystalline and the surface layer is polycrystalline or microcrystalline; energy dispersive $\mathrm{x}$-ray spectroscopy detects roughly $1 \%$ sulfur impurities in the disordered layer but none in the core. ${ }^{6}$ The TEM images and diffraction patterns obtained from annealed samples are similar. ${ }^{6}$ The ns-formed structures likewise have a crystalline core, but the disordered layer is even thinner (200 $\mathrm{nm}$ or less) and covers only parts of the structures; the tips of the structures are free of visible disorder. Although the bases of the ns-formed structures [visible in Fig. 1(f)] cannot be observed in TEM, they are visible to ion channeling, which averages over the projected surface. Hence the observed good channeling indicates that even at the bases, the surface of the ns-formed structures cannot be as disordered as that of the fs-formed structures.

How do such different structures have such similar optoelectronic properties? In both the ns- and fs-formed structures, sulfur is required for strong below-band gap absorptance, and thermal annealing reduces the absorptance strongly while reducing the observable sulfur content by only $20 \%$ and having no obvious effect on the crystallinity. The disordered layer covering the fs-formed structures is not essential for below-band gap absorption, as both TEM and RBS indicate that the ns-formed structures are nearly single crystal. Most likely, laser structuring incorporates sulfur into silicon in an optically active configuration; then, during thermal annealing, some of the sulfur is deactivated by complexing with other defects or by forming precipitates. Sulfur is known to stabilize ion implantation-induced damage against thermal annealing, ${ }^{9}$ so it is plausible that sulfur can form relatively stable defect complexes. Annealing at $875 \mathrm{~K}$ for 45 min would indeed permit both defect annihilation in the silicon lattice ${ }^{10}$ and diffusion of sulfur over hundreds of nanometers; ${ }^{11}$ the observed reduction in sulfur concentration most likely comes from sulfur diffusing to depths greater than can be observed with RBS.

Such an optically active configuration of sulfur may be able to exist in either the single crystal ns-formed structures Downloaded 21 May 2004 to 128.103.60.225. Redistribution subject to AIP license or copyright, see http://apl.aip.org/apl/copyright.jsp or the highly disordered fs-formed structures; the deactivation process must not require a significant increase in the crystallinity of the fs-formed structures. Alternatively, different optically active configurations of sulfur could be present in the fs-formed and ns-formed structures, although none of our results directly suggest this interpretation.

In the ns-formed structures, the sulfur incorporation process is probably similar to gas immersion laser doping, ${ }^{12}$ in which a semiconductor is doped by melting the surface with ns laser pulses in the presence of a gas containing the desired dopants. The dopants are incorporated into the melt and rapid solidification that follows laser melting can produce highly supersaturated solid solutions. ${ }^{13}$ Sulfur may be incorporated into the fs-formed structures by a similar process; the fs laser fluences used are not far above the ablation threshold, and so a molten layer forms at the surface after the laser-induced plasma recombines and the electrons and lattice equilibrate. ${ }^{14}$

In summary, laser microstructuring of silicon surfaces in the presence of $\mathrm{SF}_{6}$ with either ns or fs laser pulses produces strong below-band gap absorption and photocarrier generation. Both types of structures exhibit these remarkable optoelectronic properties in spite of significant differences in crystallinity and morphology. Our results suggest that laser structuring and sulfur doping of silicon is a robust way to extend the photoresponsivity of silicon into the near-infrared.

We thank J. Chervinsky, J. Harper, E. Hoke, J. Sage, and M. Sheehy for experimental assistance, and Professor C. M. Friend, Professor E. Kaxiras, Professor J. Leonard, Professor W. Paul, and Professor F. Spaepen for helpful discussions. Work at Harvard was supported by the Harvard MRSEC (NSF/DMR-98-09363), the Dept. of Energy (DOE DE FC36 01GO11053), and the Army Research Office (DAAD19-991-0009). Work at LLNL was performed under the auspices of the U.S. Dept. of Energy by the Univ. of CA, Lawrence Livermore National Laboratory under Contract No. W-7405Eng-48.

${ }^{1}$ S. R. Foltyn, in Pulsed Laser Deposition of Thin Films, edited by D. B. Chrisey and G. K. Hubler (Wiley-Interscience, New York, 1994), Chap. 4, and references therein.

${ }^{2}$ T. H. Her, R. J. Finlay, C. Wu, S. Deliwala, and E. Mazur, Appl. Phys. Lett. 73, 1673 (1998).

${ }^{3}$ A. J. Pedraza, J. D. Fowlkes, and D. H. Lowndes, Appl. Phys. Lett. 74, 2322 (1999)

${ }^{4}$ C. Wu, C. H. Crouch, L. Zhao, J. E. Carey, R. Younkin, J. A. Levinson, E. Mazur, R. M. Farrell, P. Gothoskar, and A. Karger, Appl. Phys. Lett. 78, 1850 (2001).

${ }^{5}$ J. E. Carey, C. H. Crouch, M. Shen, M. A. Sheehy, C. M. Friend, and E. Mazur (unpublished).

${ }^{6}$ C. H. Crouch, J. E. Carey, M. Y. Shen, E. Mazur, and F. Génin, Appl. Phys. A (to be published).

${ }^{7}$ R. Younkin, J. E. Carey, E. Mazur, J. A. Levinson, and C. M. Friend, J. Appl. Phys. 93, 2626 (2003).

${ }^{8}$ M. Sheehy, L. Winston, J. E. Carey, E. Mazur, and C. M. Friend (unpublished).

${ }^{9}$ R. Wilson, J. Appl. Phys. 55, 3490 (1984).

${ }^{10}$ A. Agarwal, H. J. Gossmann, D. J. Eaglesham, L. Pelaz, D. C. Jacobson, J. M. Poate, and T. E. Haynes, Mater. Sci. Eng., A 253, 269 (1998).

${ }^{11}$ The diffusion coefficient of $\mathrm{S}$ in $c$-Si at $875 \mathrm{~K}$ was estimated to be 1.6 $\times 10^{-13} \mathrm{~cm}^{2} / \mathrm{s}$ by extrapolation from data in S. M. Sze, Physics of Semiconductor Devices, 2nd ed. (Wiley, New York, 1981), p. 68.

${ }^{12}$ P. G. Carey and T. W. Sigmon, Appl. Surf. Sci. 43, 325 (1989).

${ }^{13}$ R. Reitano, P. M. Smith, and M. J. Aziz, J. Appl. Phys. 76, 1518 (1994).

${ }^{14}$ V. I. Emel'yanov and D. V. Babak, Appl. Phys. A 74, 797 (2002). 